\title{
Scenario planning for climate change adaptation for natural resource management: insights from the Australian East Coast Cluster
}

\begin{abstract}
Natural resources and inherent ecosystem services have long been under pressure from unsustainable exploitation further exacerbated by climate change impacts. Managing natural resources in the Australian context is also a complex task because it involves a raft of stakeholders subjected to ongoing institutional changes and reductions in funding for programme implementation. This paper explores the use of scenario planning as a suitable tool to deal with the uncertainty and complexity inherent to natural resource management. Specifically, it reports on the development and application of explorative scenarios (multiple plausible futures) involving six natural resource management organisations and their communities of practice operating along the East Coast of Australia. Scenarios were developed based on two key drivers of change, namely: maturing approach to natural resource management; and community driven climate change action, to test the robustness and flexibility of a suite of existing strategies, policies and targets. Findings indicate that explorative scenarios were useful in the identification of strategies that may result in perverse or negative impacts under different futures; guide selection of different approaches in response to unexpected events; encourage a forwardlooking approach rather than relying on past experiences only; create flexible, robust strategies that are better able to deal with shocks and surprises; provide participating policy owners with an opportunity to consider future contexts for their policies to play out in; and, ascertain a range of possible pathways to achieve a vision or goals depending on changed circumstances.
\end{abstract}

Keywords foresight, uncertainty, collaborative planning, environmental planning, ecosystem services

\section{Introduction}

The uncertainty inherent to climate science makes it difficult to determine the extent to which climate change will impact ecosystem services (ES) (Scholes 2016). This uncertainty is compounded when other drivers of change are at stake such as urbanisation and population growth (McPhearson et al. 2015). There is also limited knowledge about how ES could assist in climate change adaptation and mitigation (Schetke et al. 2018). Yet, it is widely acknowledged that ecosystem services can assist in the achievement of many Sustainable Development Goals, including Climate Action (Wood et al. 2018).

Australia is no exception with climate change likely to impact both marine and terrestrial ecosystems in a number of ways. Increased mean temperatures, change in rainfall patterns and extreme weather events are likely to impact the country's ecosystems morphology, community composition, geographic distribution of species, life cycles, productivity and give rise to diseases (Reisinger et al. 2014). It is also recognised that the 
national natural resource base (e.g., water quality, biodiversity, soil health) has declined over the last decades (Lockwood et al. 2010). Ecosystem management in Australia is largely the responsibility of natural resource management (NRM) organisations working in partnership with governments and communities. NRM organisations are tasked with responsibilities relating to managing land, water, soil, animals and plants as well as climate change adaptation (Adams et al. 2017); thereby having a key role in sustaining and maintaining a range of ecosystem processes and functions which in turn contribute to ES (Costanza et al. 2017). Additionally, Australian NRM organisations operate under significant institutional uncertainty regarding the availability of human and financial resources that affect the implementation of on-ground programmes targeting conservation, restoration and rehabilitation of ecosystems (Vella et al. 2015, Serrao-Neumann, Cox, and Low Choy 2019).

The high level of environmental and institutional uncertainty affecting the activities of Australian NRM organisations warrants the use of scenario planning for informing climate change adaptation because of its known suitability to contexts of high uncertainty, rapidly changing situations, and low ability to control the forces of change (Cork, Delaney, and Salt 2004, Pearson et al. 2010). Scenario planning constructs scenarios as descriptions of possible alternative futures and/or the causal events and trajectories that can lead to different future states (Amer, Daim, and Jetter 2013, Börjeson et al. 2006). These scenarios are often presented in the form of narratives or storylines (Amer, Daim, and Jetter 2013), and are not predictions of what the future will look like but plausible representations of possible futures based on drivers of change (Oteros-Rozas, MartìnLópez, et al. 2015).

Over the last decade, there has been a rise in popularity in scenario planning practice, research and literature, including for climate change adaptation (Bohensky et al. 2011, Serrao-Neumann and Low Choy 2018, de Coninck et al. 2018) and ES (OterosRozas, Martìn-López, et al. 2015, Sandhu et al. 2018, Harmáčková and Vačkář 2018). This rise in interest has led to a proliferation in scenario planning methodologies (Varum and Melo 2010). Scenario planning methodologies can be grouped under three main categories: predictive, explorative, and normative scenario planning. This paper reports on the use of explorative scenario planning that explores situations or developments, which may be regarded as future possibilities, and generally seek to include a variety of perspectives. Usually a group of scenarios are developed to collectively represent a wide scope of potential future developments. For this reason, explorative scenario planning is geared towards questions about 'what can happen?' (Börjeson et al. 2006). 
Explorative scenario planning methodologies are often carried out to test the robustness or adaptability of different actions, policies or strategies (Carlsson-Kanyama et al. 2008). Testing strategies or policies in different scenarios to see how they might be affected by future developments or events that are outside the scope of control of an organisation reflects on their robustness or adaptability (Börjeson et al. 2006).

Alternatively, explorative scenario planning can focus on internal factors within the control of an organisation (e.g., different policy or strategic approaches). The result reflects on a range of possible consequences that may emerge from strategic decisions or policies (Börjeson et al. 2006).

There are also limitations on the use of scenario planning. Many new emerging methods in scenario planning of integrating quantitative and qualitative data are still being developed, and may require many technical and institutional capabilities (Oteros-Rozas, Martìn-López, et al. 2015). For example, not all agencies have the physical and human resource capacity to process large datasets. This may be due to limited access to the technologies and skills required, and the availability of datasets themselves. Additionally, the integration of input from stakeholders as well as other experts that are not directly affected by plan developments remains a methodological challenge because scenario planning relies on institutional support and individual interest to participate (Oteros-Rozas, Martìn-López, et al. 2015, Means et al. 2010).

Nevertheless, there is growing recognition of the need for environmental management to consider multiple environmental and social processes over multiple scales of time and space. This has led to a greater tendency for planning for environmental management to consider thresholds, or tipping points in environmental systems (Cork, Delaney, and Salt 2004). For issues of environmental management, scenario planning can help to explore social ecological feedbacks and potential surprises that cannot be easily replicated in formal modelling approaches. Data on locally perceived changes and impacts of possible futures gleaned through scenario planning can be useful in achieving improved understanding of current and future conditions and dynamics (Oteros-Rozas, MartínLópez, et al. 2015).

This paper adds to a growing body of studies discussing the applicability of scenario planning for strategic planning and decision-making concerning ES in Australia (Sandhu et al. 2018, Bohensky et al. 2011) and elsewhere (Oteros-Rozas, Martìn-López, et al. 2015, Harmáčková and Vačkář 2018). The paper contributes to further advance the use of scenario planning in this context by exploring how it can inform the implementation of more flexible and robust strategies for natural resource management planning for climate 
change adaptation, especially under current and future institutional and environmental uncertainty.

\section{Research approach}

\subsection{Research design}

At the time of this research there were 56 NRM organisations in Australia (Australian Government 2014) that were grouped into eight clusters for the purpose of the Natural Resource Management Climate Change Impacts and Adaptation Research Grants Program (2012-2016). This paper focuses on the East Coast Cluster, comprising six regional organisations on the east coast of the states of Queensland (QLD) and New South Wales (NSW) (see Figure 1).

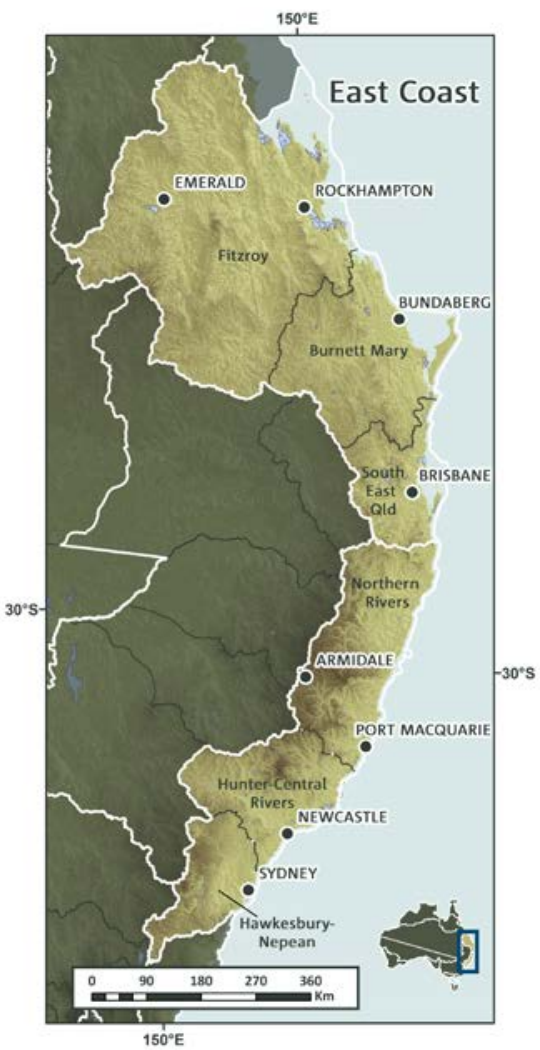

Figure 1. Six NRM regions comprising the East Coast Cluster: Fitzroy Basin, Burnett Mary, South East Queensland, Northern Coast, Hunter and Greater Sydney 
The East Coast Cluster provide a suitable case study area for the investigation of ES related issues because its area, population and bio-physical characteristics vary widely. The Cluster hosts two major capital cities (Brisbane and Sydney) and associated metropolitan areas, RAMSAR sites, major river systems, biodiverse rich world heritage forests, unique islands and coastal ecosystems, marine parks (including the southern end of the Great Barrier Reef), and significant agricultural areas (Australian Government 2016). The combined six NRM regions provide a range of ES to an estimated human population of nearly 10 million people (Australian Bureau of Statistics 2016). On the other hand, the Cluster's ES are under ongoing pressure from increased urbanisation and associated resource demand with the add-on impacts from climate change.

A research consortium involving four research institutions and two state government agencies was created in 2012 to carry out the Climate Change Adaptation for NRM in East Coast Australia Project (thereafter referred to as the project) in partnership with the six NRM regional bodies comprising the East Coast Cluster. The three-year project aimed to foster and support an effective community of practice for climate change adaptation within the East Coast Cluster. The scenario planning process discussed in this paper was led by one of the research consortium members responsible for the engagement activities with the communities of practice involving the Cluster planners.

Adopting an action research approach (Reason and Bradbury 2006), engagement activities involving the Cluster planners were held between May 2013 and June 2015 and comprised a series of five two-day workshops and ongoing discussions via shared mailing lists. Two out the five workshop series (one workshop day in November 2014 and another in April 2015) were dedicate to the scenario planning process. Participants in the scenario planning workshops included planners from the six East Coast NRM organisations, East Coast Cluster researchers, local government personnel and industry stakeholders. There were 21 and 17 participants in workshop 1 and 2, respectively.

Ideally, a scenario planning process would be held for each NRM region enabling NRM organisations and their key stakeholders to work together to assess strategies for their region. However, it was not logistically and financially possible to assemble such a large group in one central location for the workshops, and there were not enough attendees from each region at the workshops to allow this to happen. Instead, workshop participants from the NRM regions were mixed throughout the four small groups and worked on assessing strategies from all regions. This was in line with the overall aim of the project which was focused on fostering and supporting an effective community of practice led by the NRM practitioners. It also concurred with the literature, which conceives 
scenario planning methods as being often interdisciplinary, and the inclusion of a diversity of worldviews, stakeholders and information across multiple spatial, temporal and institutional scales (Oteros-Rozas, Martín-López, et al. 2015). Hence, the scenario planning process functioned as a training session and provided material for a subsequent 'how to do scenario planning' package produced at the conclusion of the project and freely available to the public.

\subsection{Overview of scenario planning process}

Figure 2 illustrates the explorative scenario planning process (Börjeson et al. 2006) adopted at the workshops. During workshop 1, participants used a focal question to identify and rank key critical drivers of change affecting NRM. The focal question guiding a scenario planning process should be relevant to current critical issues facing the organisation, and broad enough to allow for wide ranging exploration of the issues. The focal question guiding the first scenario planning workshop was:

What current and future drivers of change will influence the East Coast Cluster in the next 25 years and which need to be taken into account in NRM planning for climate change adaptation?

\section{Explorative Scenario Planning - key steps}

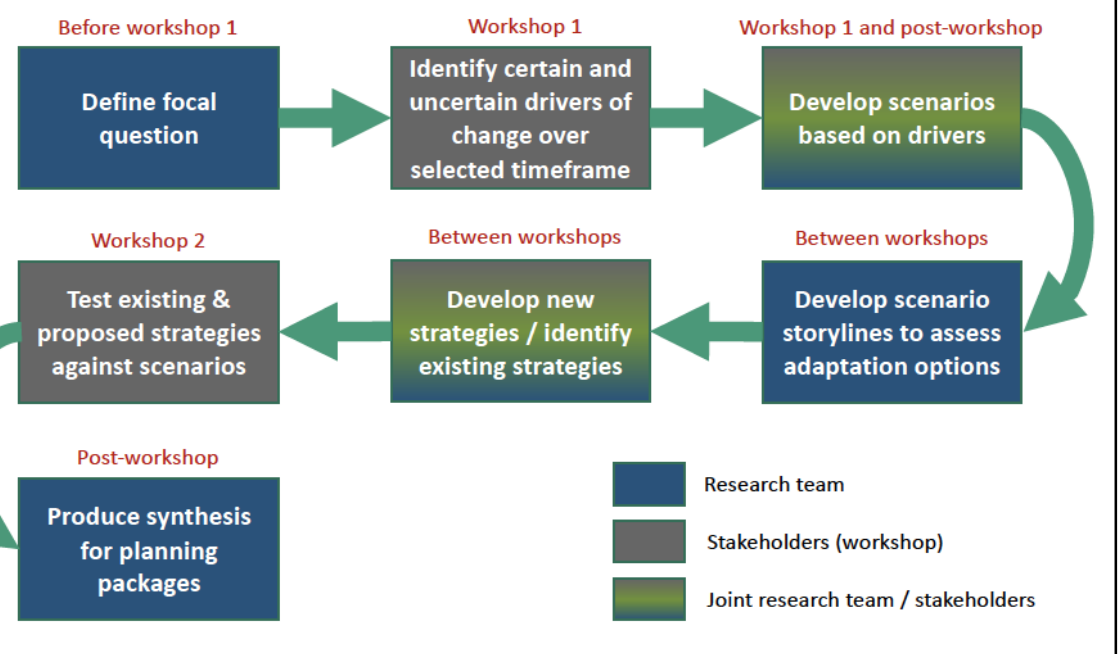

Figure 2. Overview of explorative scenario planning process 
Drivers of change were defined as environmental, social, economic, political and technological factors (natural or human-induced) that directly or indirectly caused a change in a system and affected several temporal and spatial levels (e.g., global, national, regional and local drivers internal or external to the system). Workshop participants ranked drivers of change according to their degree of uncertainty (an expression of the likelihood of a specific driver influencing change now and in the future - uncertainty can result from lack of information or from disagreement about what is known or even knowable) and importance (the degree or relative significance to which a particular driver influences or will influence a specific sector).

A series of fact sheets were provided to participants prior to the workshops to set the context and provide information related to latest scientific information and issues affecting the Cluster. Fact sheets covered the following topics: explorative scenario planning methodology; climate change impacts; demographics; and institutional arrangements for natural resource management, urban and regional planning and disaster management. Informed by the fact sheets and their tacit knowledge, participants identified ten critical drivers of change (highly uncertain and highly important) that could influence the East Coast Cluster in the next 25 years and needed to be considered in NRM planning for climate change adaptation. They then voted to select the two drivers that should be used to construct the scenario matrix. Participants opted for not having an axis specifically dealing with climate change impacts because they assumed a future where impacts were unavoidable, and demanded action. This resulted in the selection of:

- Community driven climate change action

- A maturing response to NRM

The two key drivers were placed along two axes and scenarios were identified for each of the four quadrants (see Figure 3). Because of logistic, time and availability constraints only two future scenarios were chosen by workshop participants for further development and analysis carried out at the second scenario planning workshop, being:

- 'Anthropocentric' scenario

- 'New paradigm' scenario 


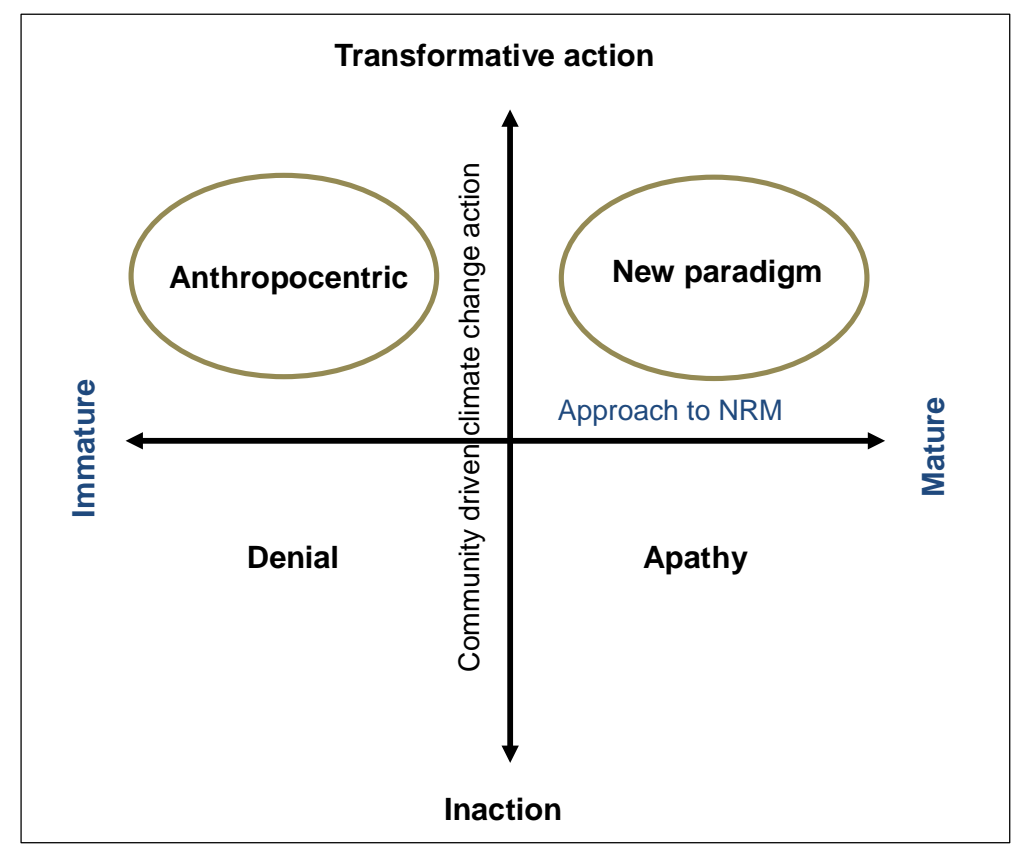

Figure 3. Scenario matrix and selected narratives to be further developed for workshop 2

Working in small groups, participants constructed elements of preliminary scenario narratives by identifying characteristics of each scenario at global, national, and cluster scales. Scenario outlines were further developed by researchers who mapped out more detailed narratives for the second workshop (see Table 1).

Table 1. Narratives for the Anthropocentric and New Paradigm scenarios - plausible futures for 2040.

\begin{tabular}{|c|c|}
\hline Anthropocentric & New Paradigm \\
\hline $\begin{array}{l}\text { Overview. A scenario characterised by a high level } \\
\text { of community driven climate change action leading } \\
\text { to political support and efforts at all scales to tackle } \\
\text { climate change, but with little investment in or } \\
\text { concern for NRM. } \\
\text { Demography. Ageing population continues to be } \\
\text { the trend across the country. Most population } \\
\text { growth results from immigration and birth rates } \\
\text { continue to be low. } \\
\text { Urban development and housing. The majority of } \\
\text { the population is concentrated in medium to large } \\
\text { cities away from vulnerable areas. Generally, } \\
\text { development is occurring away from the coast } \\
\text { because of increased rates of storm surges and }\end{array}$ & $\begin{array}{l}\text { Overview. A scenario characterised by a high level } \\
\text { of community driven climate change action leading } \\
\text { to political support and efforts at all scales to tackle } \\
\text { climate change, along with increased focus on } \\
\text { NRM, manifest through increased community } \\
\text { concern and action, as well as improved } \\
\text { institutional and governance arrangements. } \\
\text { Demography. Population growth has stabilised and } \\
\text { concentration is spread among many regional } \\
\text { towns as opposed to capital cities. } \\
\text { Urban development and housing. There is } \\
\text { increased sharing of common resources and focus } \\
\text { on net zero houses. Mixed landuse has increased } \\
\text { in regional towns with a trend towards meeting } \\
\text { needs locally. }\end{array}$ \\
\hline
\end{tabular}




\section{Anthropocentric}

flooding, and from inland areas affected by more frequent heatwaves.

Environmental change. Significant impacts from extreme weather events on sensitive ecosystems cannot be rehabilitated. Natural assets continue to be under pressure from urbanisation and agriculture and there is a general lack of concern for the viability of ES.

Economy. Employment rates are relatively stable due to larger government workforce, but underemployment continues to grow. While income levels are stable, living and energy costs are increasing.

Technology. There is a focus on engineering solutions to address climate change impacts. The development of the nuclear power industry has been ignited as an alternative to curb GHG emissions.

Community. There is widespread community burnout and disengagement accelerated by continual action required to deal with failures in managing climate change impacts and ES. Greate concentration and movement of population toward cities has led to loss of social cohesion. Volunteer rates continue to be down with greater reliance on governments to deliver services.

Positive trends. Risk assessment approaches are common, leading to improved understanding of likely impacts. Some decreases in emissions have occurred and remaining emissions are largely mitigated. Most of the population is 'protected' from climate change impacts by engineering solutions. Many people feel secure as their lifestyle can remain relatively unchanged. Some marginal agricultural lands that have been abandoned are starting to regenerate.

Negative trends. Limited flexibility in the application of NRM funding has led to a narrowe focus on specific issues rather than on overall threats. Sensitive ecosystems have been lost due to extreme weather events. There are low rates of volunteerism and funding along with low rates of support for NRM. Water conflict has intensified due to ongoing droughts and floods. There is lack of community involvement in decisions leading to gradual loss of capacity and resilience. Any reductions in the scale of government could result in widespread unemployment and no other agencies able to replace government functions.

\section{New Paradigm}

Environmental change. Rehabilitation of impacted ecosystems is progressing to improve resilience through ES. Mixed farming is now a common practice in agriculture. There is greater focus on managing ecosystems for securing multiple ES. Economy. There are lower levels of workforce participation because of general decline in formal economic activities, e.g. retail significantly reduced. Incomes are relatively low with a prevailing shared economy, especially for innovative good practice.

Technology. There have been advances in sustainable technologies and eco-innovation, including renewable energy and storage and agricultural technologies.

Community. There are higher levels of volunteerism but also higher societal reliance on volunteers to provide services. Communities became more politically engaged and effective consultation is now required on all policies.

Positive trends. There have been improved governance models resulting in improved communication and reduced 'silo' mentality. There is increased community input and involvement leading to improved capacity and social resilience. Regional focus has improved local knowledge and management and lead to policy solutions well adapted for each location. The focus on broader indicators of progress contributed to better understanding of links between environment, social and economic issues.

Negative trends. Some business sectors have collapsed or declined significantly, e.g. insurance, retail. There is strong reliance on community volunteers which may result in reduced government provision of services over time. The need for extensive consultation sometimes results in delayed responses or policy change. Reduced travel between regions has resulted in some insularity and parochial thinking. Multiple regional approaches to innovation has lead to lack of consistency and inhibited take-up of best solutions. Some people are feeling disenfranchised as the shift in values means their skills are not desired.

Each NRM region then identified 6 existing strategies to be tested against these two scenarios during the second workshop (see a list of topics covered by strategies in Table

2). 
Table 2. Overview of topics covered by existing strategies tested against the two scenarios

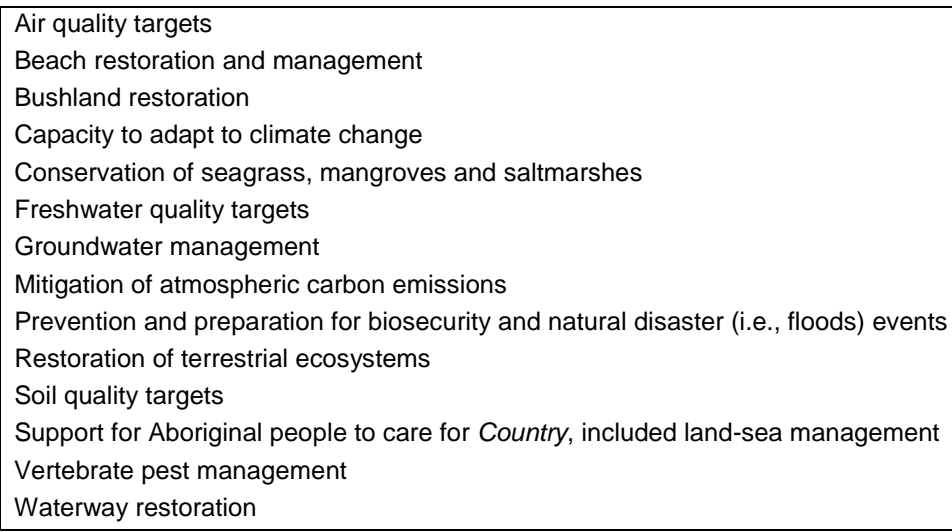

While scenario narratives were provided to participants at least a week before the second workshop, due to participants' time constraint, narratives were not evaluated prior to the workshop. Feedback on narratives provided by participants during the workshop. however, were incorporated in the final version of the narratives. Participants at the second workshop focused on the assessment of assessed existing strategies against a series of 'what if' questions for each scenario, namely:

- To what extent will this option enable the East Coast to deal with future major natural hazards?

- To what extent will this option enable the East Coast to deal with future shocks and surprises (e.g..$_{2}$ economic downturn, collapse of the international and national tourism industry, dramatic changes to oil availability)?

- To what extent does this option represent the best use of public money?

- To what extent will this option have a negative impact on the East Coast?

- To what extent will this option assist the East Coast to fulfil its vision?

Participants were also asked to consider the following issues when answering the questions:

- How difficult would it be to implement the strategy / action under the scenario?

- If the strategy / action could be implemented, would the result be desirable?

-What aspects of the scenario would impact on implementing the strategy?

The above questions are specifically devised to encourage participants to consider future thinking in their assessment. Due to time limitations, only a few existing strategies 
were tested against both scenarios. As a group, participants then identified signposts, shocks and surprises that might occur on the 'roadmap' from the present into the future.

\section{Results and Discussion}

Exploring multiple plausible future situations can help to expand the sphere of thinking of those carrying out scenario planning and better prepare them for those eventualities should they materialise in the future. It can identify new issues or challenges that may develop in the future. This can in turn improve decision-making processes, and stimulate creative and flexible ways to meet goals and address vulnerabilities (Amer, Daim, and Jetter 2013). As expected, the strategies were assessed differently under the two scenarios, particularly in relation to how they would be implemented or the level of support that the strategies would have from the broader community. Overall, no strategies were identified as having negative impacts, but participants highlighted some ways that strategies could be improved or would need to be modified under the different scenarios. A summary of key findings with implications for ES are presented next (see Table 3 for assessment examples).

Table 3. Summary of key results from scenario assessment

\begin{tabular}{|c|c|}
\hline Selected strategies, policies and targets & Overall assessment examples \\
\hline $\begin{array}{l}\text { Strategy } 3.1 \text { public land, natural foreshore areas, } \\
\text { e.g., mangroves and replanting } \\
\text { Priority waterway restoration } \\
\text { 3.1.1 Identify priorities for investment. } \\
\text { 3.1.2 Develop incentive projects for implementation. } \\
\text { 3.1.3 Promote and disseminate educational } \\
\text { resources for waterway management. } \\
\text { 3.1.4 Develop targeted and strategic cross tenure } \\
\text { riparian weed programs. } \\
\text { 3.1.5 Build partnerships with local government, } \\
\text { agencies and community. }\end{array}$ & $\begin{array}{l}\text { 'New Paradigm' - its strategic, collaborative focus, } \\
\text { enables a more flexible approach; it assists with } \\
\text { improving water quality and reduces velocity of } \\
\text { water and flooding potential and impacts; it } \\
\text { improves ES and domestic food production with } \\
\text { water quality, as well as health and wellbeing / } \\
\text { amenity of people; it enables greater community } \\
\text { participation and uptake of restoration projects. } \\
\text { 'Anthropocentric' - vulnerable to shocks; labour } \\
\text { intensive so funding/volunteer efforts are high; it } \\
\text { needs more information on how investments will be } \\
\text { prioritised (e.g., criteria for location and values); it is } \\
\text { beneficial compared to hard engineering but needs } \\
\text { strong evidence base to support projects and } \\
\text { funding. }\end{array}$ \\
\hline
\end{tabular}




\begin{tabular}{|c|c|}
\hline Selected strategies, policies and targets & Overall assessment examples \\
\hline $\begin{array}{l}\text { Vision } 2035 \\
\text { The region makes an equitable contribution to state } \\
\text { and national air quality targets and mitigation } \\
\text { measures to reduce the atmospheric carbon level. } \\
2020 \text { Target } 1 \\
\text { Participation in schemes that encourage bio- } \\
\text { sequestration, using the carbon storage capacity of } \\
\text { soils and vegetation, will exceed the } 2015 \text { baseline. } \\
\text { Primary producers and other land managers will } \\
\text { participate in and benefit from their involvement in } \\
\text { carbon farming initiatives. }\end{array}$ & $\begin{array}{l}\text { 'New Paradigm' - great idea but actual impact is not } \\
\text { high. Mitigation is a nationally and internationally } \\
\text { driven priority - to be successful needs to be } \\
\text { supported in all jurisdictions. What happens in one } \\
\text { area is useful but in terms of dealing with hazards - } \\
\text { hazards will happen anyway due to locked in } \\
\text { impacts. Mitigation will reduce but not eliminate the } \\
\text { risks. Will only be effective if replicated nationally } \\
\text { and internationally. Recognising responsibility and } \\
\text { effective process but not good on its own. Target } 1 \\
\text { needs to be expressed numerically. There is } \\
\text { nothing to say what the target is, it needs to be a } \\
\text { numerical target to make it more binding, more } \\
\text { details on by whom, where etc (e.g. carbon farming } \\
\text { initiatives). } \\
\text { It needs to make sure there are no perverse } \\
\text { outcomes - e.g. knowledge of catchment yields for } \\
\text { water supply and balance against these. It needs to } \\
\text { consider risks - e.g. corridors are potential } \\
\text { pathways for weeds and pests to move through. It } \\
\text { needs to add to extent and condition but not } \\
\text { change other existing biodiversity values- consider } \\
\text { provenance etc. }\end{array}$ \\
\hline $\begin{array}{l}\text { Threshold: Seagrass, mangroves and saltmarsh } \\
\text { Seagrass (as at 1998) 18,391ha Mangrove (as at } \\
\text { 2001) 22,590ha } \\
\text { Local action: } \\
\text { 7.1 Provide Environmentally Friendly Moorings } \\
\text { particularly high density seagrass areas (Map 7). } \\
\text { Planning action: } \\
\text { 7.2 Undertake catchment management planning as } \\
\text { part of a Water Quality Improvement Plan for SEQ } \\
\text { to reduce sediment from urban and rural areas } \\
\text { (Map 1.0). } \\
\text { 7.3 Plan land use in areas needed for mangroves } \\
\text { and other critical habitats to retreat from sea level } \\
\text { rise (Map 4.0). } \\
\text { 7. } 4 \text { Consider the potential impacts on the Moreton } \\
\text { Bay Marine Park boundaries from sea level rise to } \\
\text { ensure RAMSAR and economic values remain into } \\
\text { the future. }\end{array}$ & $\begin{array}{l}\text { 'Anthropocentric' - Absence of NRM funding } \\
\text { creates community engagement in pockets. If there } \\
\text { is no money to implement - there is very little } \\
\text { impact (depending on the specific adaptation } \\
\text { strategy e.g. engineering). } \\
\text { If the community is involved, maybe the community } \\
\text { can take more responsibility - but it depends on the } \\
\text { type of action (some solutions re expensive and } \\
\text { complex and community cannot fund them without } \\
\text { government support). "I don't think you can have a } \\
\text { strong community without strong government and } \\
\text { support". } \\
\text { "Anthropocentric" is what is happening now but we } \\
\text { don't have high level community action. There is no } \\
\text { need for NRM - the community is doing it, but NRM } \\
\text { is not supported by authorities. } \\
\text { Strategy is fine but delivering it under } \\
\text { Anthropocentric scenario will not work. }\end{array}$ \\
\hline
\end{tabular}




\begin{tabular}{|c|c|}
\hline Selected strategies, policies and targets & Overall assessment examples \\
\hline $\begin{array}{l}\text { Objective } 7 \\
\text { Support Aboriginal people to care for Country and } \\
\text { share traditional land management knowledge. } \\
\text { Action:7.3 } \\
\text { Develop long-term community projects that deliver } \\
\text { employment outcomes for the Aboriginal } \\
\text { community. } \\
\text { Action } 7.4 \\
\text { Encourage the Aboriginal community to develop } \\
\text { partnerships with other stakeholders through } \\
\text { facilitation and negotiation of proposed projects. }\end{array}$ & $\begin{array}{l}\text { 'New Paradigm' - Loose association -it assist in } \\
\text { improving values and connection to land, general } \\
\text { community understanding values of landscape, but } \\
\text { there is not specific link to any hazard } \\
\text { management. For example, management of } \\
\text { bushfires in landscape - do we follow traditional } \\
\text { practices? Lachlan trialling firesticks (HN) - it is not } \\
\text { about just applying traditional knowledge because } \\
\text { connections to land are lost and the landscape is } \\
\text { also different - e.g. temperature and plants are } \\
\text { different. It needs to be relearnt because of different } \\
\text { context. } \\
\text { It needs to broaden thinking about how to adapt to } \\
\text { a changing environment and what can be learned } \\
\text { about managing land and how this relates to } \\
\text { challenges in the future regarding adaptive mindset. } \\
\text { It should include more about building capacity. } \\
\text { There are good stories such as having lived } \\
\text { through climate change and ice age - it needs to } \\
\text { think about these time frames and relate this to } \\
\text { future challenges. }\end{array}$ \\
\hline $\begin{array}{l}\text { Attribute: Terrestrial ecosystems } \\
\text { Objective: Maintain the extent, composition, } \\
\text { structure and function of terrestrial ecosystems. } \\
\text { Strategy (practice): Promote land and water } \\
\text { management practices to minimise the impacts of } \\
\text { weed and pest species. }\end{array}$ & $\begin{array}{l}\text { 'New Paradigm' - There is an issue with } \\
\text { maintaining extent - to maintain is to limit or } \\
\text { eliminate the ability to adapt to future major natural } \\
\text { hazards (it will not have opportunity to adapt to a } \\
\text { changing climate). It needs to improve the extent, } \\
\text { composition etc, or capacity to. Practice should be } \\
\text { broadened to cover other areas of NRM impacts, } \\
\text { not just weeds and pests. Maintaining does not } \\
\text { reflect that condition is already poor in most cases } \\
\text { and actions need to take place that support } \\
\text { changed climate conditions. }\end{array}$ \\
\hline $\begin{array}{l}\text { Goal } 1 \\
\text { Adapting to a changing climate: } \\
\text { Fostering capacity to adapt to change, ensuring } \\
\text { landholders are informed and working towards } \\
\text { resilience. } \\
\text { Strategy } 1 \\
\text { Deliver information and knowledge services that } \\
\text { support and enable customers to improve decision } \\
\text { making. } \\
\text { Action } 1.1 \\
\text { Extension programs fostering capacity to adapt to } \\
\text { change (relate to "change" generally, rather than } \\
\text { climate change only). }\end{array}$ & $\begin{array}{l}\text { 'New Paradigm' - Greater sense of community may } \\
\text { result in people helping each other - lack of } \\
\text { insurance may lead to more people likely to help, or } \\
\text { be helped to move out of danger areas (fire, flood, } \\
\text { erosion). Community banks could be created - e.g. } \\
\text { alternative to traditional insurance, community } \\
\text { could set up mutual fund e.g. councils are self } \\
\text { insuring, mutual fund to help everyone. } \\
\text { 'Anthropocentric' - It needs to provide the } \\
\text { foundation from which adaptation could go further } \\
\text { through knowledge base in the community. It can } \\
\text { build capacity within local community to be able to } \\
\text { adapt to local hazards, prevents problem with lack } \\
\text { of investment in NRM to implement capacity } \\
\text { building in local community. This is critical to further } \\
\text { adaptation programs. }\end{array}$ \\
\hline
\end{tabular}

\section{a) Identifying strategies that may result in perverse or negative impacts}

Scenario planning is not a panacea, and scenarios themselves will not provide solutions to problems but rather inform decisions and/or strategies to address problems (Varum and Melo 2010). This applicability of scenario planning was evident when 
participants identified strategies that seemed reasonable under current conditions but could potentially have perverse or negative impacts under different futures, or needed to be implemented in different ways. For example, when assessing a policy related to waterway restoration (natural foreshore areas and mangroves) participants found that the policy was functional under the 'New Paradigm' scenario but not as efficient under the 'Anthropocentric' scenario. They attributed this limitation to the fact that the policy did not assist in dealing with future shocks and surprises because of its reliance on available funds and volunteers to be implemented, especially in periods of economic downturn. Notably, this assessment reviews the importance of considering climate change impacts in policy design implementation to enable the evaluation of adaptive responses. For example, sea level rise should have been considered in this policy because it will affect mangrove growth. Whilst mangrove planting is a positive ecosystem-based strategy, the success of such initiatives may be overshadowed by climate change impacts because they will affect growth rates at differing locations. These adaptation limits are important to be taken into consideration to both set achievable targets and understand the risks of failure involved in well-intentioned strategies.

Another exemplar was a policy intention aimed at improved air quality targets and mitigation measures seeking to achieve atmospheric carbon levels. Participants found that under the 'New Paradigm' scenario this policy was unlikely to deal with future hazards because it required concerted national and international efforts for it to be effective along with clearly identified targets to be achieved (i.e., targets needed to be numerically expressed to enable their measurement and evaluation).

\section{b) Guiding selection of different approaches in response to unexpected events}

Environmental and social change will continue to challenge ES management. These challenges include forecasted climate change impacts that will affect south-east Australia, such as change in annual rainfall averages leading to floods and droughts, increased temperature averages with longer and more frequent heatwaves, and sea level rise leading to coastal inundation and salt water intrusion (Hope et al. 2015). These also include social changes such as population growth, and changes in public expectations related to ES.

Participants confirmed how considering strategies under different scenarios provided useful insights to choose different implementation approaches in response to unexpected events. For example, the assessment of a policy aiming at the conservation of seagrass, mangroves and saltmarshes indicated how it needed to be strengthened to improve its 
effectiveness under the 'Anthropocentric' scenario. Participants highlighted the need to improve community engagement and understanding of the importance of NRM for the policy to be effective in dealing with future hazards and shocks and surprises. They also identified the need for a greater government role in supporting and funding for NRM because 'you cannot have a strong community without a strong government support'. Without these conditions the policy was likely to achieve results only in certain pockets where the community was driving actions rather than at a larger spatial scale.

c) Encouraging a forward-looking approach rather than relying on past experiences only

Future scenarios developed through explorative methodologies are often set in distant futures and are constructed to span a wide scope of possible developments so that they can be used to explore developments that may need to be taken into consideration (Börjeson et al. 2006). Planning while the climate is changing requires a forward-looking approach, where past experience may not be a reliable guide to effective action for the future. An exemplar of this need was a policy aimed at supporting Aboriginal people to care for Country and share traditional land management knowledge. In this case, participants found that even under the 'New Paradigm' scenario (a scenario characterised by a mature approach to NRM and community driven action for climate change adaptation) the policy was not suitable to deal with future natural hazards. For it to be effective, this policy needed to strengthen its link between Aboriginal values and connection to land, and general community understanding of landscape values with specific hazard management. For example, bushfire management techniques needed to not only be based on traditional practices but also consider the changed landscape in which they were rolled out (e.g., different temperatures and plant composition). Hence, it required some considerable relearning and acknowledgment of differing future contexts.

d) Creating flexible, robust strategies that are better able to deal with shocks and surprises

Scenario planning is one part of an adaptive strategic planning process that is forward-looking and explicitly considers the robustness and flexibility of strategies under different possible futures, and different pathways to achieving a goal or vision (Malekpour et al. 2017, Beh, Maier, and Dandy 2015). Shocks and surprises cannot - by definition be predicted, but considering multiple futures can help to create flexible, robust strategies that are better able to meet surprises should they eventuate. Additionally, for issues of environmental management, scenario planning can help to explore social ecological feedbacks and potential surprises that cannot be easily replicated in formal modelling approaches. Data on locally perceived changes and impacts of possible futures gleaned 
through scenario planning can be useful in achieving improved understanding of current and future conditions and dynamics (Oteros-Rozas, Martín-López, et al. 2015). Applying the two scenario narratives participants were able to distinguish how their policies were likely to achieve intended outcomes under different futures. In most cases, currently conceived policies were not able to deal with future situations and needed adjustments to improve their robustness.

For example, a policy seeking to maintain and conserve terrestrial ecosystems was deemed insufficient to deal with future shocks and surprises under the 'New Paradigm' scenario because it 'limited or eliminated the ability to adapt to future major natural hazards'. This specific policy needed to cover a wider breadth to also allow for the improvement, and not only maintenance (e.g., to maintain does not acknowledge that current ecosystem conditions are already poor), of current extent of ecosystems, along with broader climate change impacts and not just invasive weeds and pests.

\section{e) Ascertaining a range of possible future pathways}

Clearly, there is more than one pathway to achieve a vision or policy goals from a given starting point under a current set of conditions and circumstances. Likewise, there will be a range of optional future pathways that will depend on changed circumstances. The workshop responses to matters of optional pathways of policy activity were largely implicit, especially when participants considered the question of how various policies under consideration may assist (or not assist) in achieving the organisation's vision for NRM. For example, in analysing a goal towards improving landowner's capacity to adapt to a changing climate, participants acknowledged that under the 'New Paradigm' scenario there could be a greater sense of community which in turn could overcome shortfalls in funding available to deal with climate change impacts (e.g., bushfires, floods) through more collaborative insurance schemes. Under the 'Anthropocentric' scenario however, the goal needed to improve the knowledge base in the community to further adaptation.

Whilst there was acknowledgement of the need to review the monitoring of NRM activities in order to adjust and adapt future policies there were no specific mention of the possible future needs change directions all together. The short and limited scenario planning process did not allow a detailed operational plan for considering adaptation pathways to be developed although there was recognition of the benefits the process provided, for example (it) "Broadens thinking about how to adapt to changing environment". 


\section{Conclusion}

The management of ES depends on a raft of management conditions and decisions operating at any one point in time. These conditions (and management decisions) will vary in the future as a consequence of changing human induced (e.g., urbanisation) and natural (e.g., climate change) environmental variations. This project has provided further evidence that exploratory scenario planning can assist NRM managers to better understand the applicability and veracity of their current policies which may not necessarily have been developed with a consideration of future circumstances and environments.

Add something on no adaptation explicitly included in the tested strategies/ actions focus on extreme events as opposed to climate change impacts. This scenario planning process did serve to illustrate a range of possible relative dangers, uncertainties and risks that were inherent in maintaining the traditional approaches to NRM. It also highlighted that under certain circumstances, some strategies may in fact jeopardise ES in the future (e.g., air quality targets, terrestrial ecosystems).

Planning does not and cannot occur with perfect knowledge and this is particularly the case with NRM. Many times, information required for planning and management is limited (i.e., data relating to baseline information as well as information used to develop projections). Sometimes stakeholders only have limited understanding of the drivers of change and the uncertainties surrounding these drivers. There are still many gaps in knowledge as to how climate change will impact ES and how ES can assist in adaptation. Hence, the adoption of a combination of scenario planning approaches is instrumental to minimise this limitation - that is, when predictive scenarios are hampered by limited availability of data/information they may need for decision-making to be supported by exploratory scenarios that bring multi-sectoral perspectives to inform decisions_add references). Such multi-sectoral perspectives (e.g., from different branches, departments within an organisation, and partner organisations) are often supported by high levels of tacit, corporate and/or professional knowledge which helps to assess options and select the most adequate ones to deal with uncertainties. For this reason, it is important to engage as wide a group of stakeholders as possible in these planning exercises.

While organisations such as NRM regional bodies and local governments host many high level professional capabilities and expertise, a lack of structures to promote and support organisational learning comprises a missing opportunity to ensure effectiveness in setting strategic solutions and decisions. In particular, the absence of a mainstreamed 
organisational learning 'culture' within an organisation may impede the continual development of skills and capabilities of staff to deal with uncertainty.

For scenario planning to be effective it needs input from the right mix of participants to ensure all important issues are covered and diverse perspectives and expertise are included. Equally, it needs the participation of policy owners and advisors to better prepare them to deal with future changes should they eventuate. Data and information from different sources may need to be collected and interpreted to develop useful scenarios. This requires time and energy. Effort is also needed to ensure participants are not restricted by biases (such as biases towards technocratic solutions), and that assumptions relating to issues are identified and acknowledged.

Whilst scenario planning has proven to be a useful tool for decision-making, particularly in strategic planning, and especially in circumstances of high uncertainty, there is a need to refine these processes. In that regard it would be informative to more fully understand the long term operational aspects of the adaptive management process with regard to how well prior scenario planning experiences prepared those responsible for policy implementation and assisted them in their selection of alternative pathways of activity aimed at achieving respective visions. To these ends, there is a need to undertake longitudinal research on the future use of their scenario planning experience by the participating policy owners and advisers in terms of their preparation for to better handle future changes (both human induced and natural). This research needs applies equally well with respect to their reviews of options and selection of adaptation pathways.

\section{References}

Adams, V. M., J. G. Álvarez-Romero, S. J. Capon, G. M. Crowley, A. P. Dale, M. J. Kennard, M. M. Douglas, and R. L. Pressey. 2017. "Making time for space: The critical role of spatial planning in adapting natural resource management to climate change." Environmental Science \& Policy 74:57-67. doi: https://doi.org/10.1016/j.envsci.2017.05.003.

Amer, Muhammad, Tugrul U Daim, and Antonie Jetter. 2013. "A review of scenario planning." Futures 46:23-40.

Australian Bureau of Statistics. 2016. 2016 Census. Commonwealth of Australia.

Australian Government. 2016. "About the East Coast." accessed April 102019. https://www.climatechangeinaustralia.gov.au/en/impacts-and-adaptation/eastcoast/.

Beh, Eva HY, Holger R Maier, and Graeme C Dandy. 2015. "Adaptive, multiobjective optimal sequencing approach for urban water supply augmentation under deep uncertainty." Water Resources Research 51 (3):1529-1551. 
Bohensky, Erin, James R. A. Butler, Robert Costanza, Iris Bohnet, Aurélie Delisle, Katharina Fabricius, Margaret Gooch, Ida Kubiszewski, George Lukacs, Petina Pert, and Eric Wolanski. 2011. "Future makers or future takers? A scenario analysis of climate change and the Great Barrier Reef." Global Environmental Change 21 (3):876-893. doi: http://dx.doi.org/10.1016/i.gloenvcha.2011.03.009.

Börjeson, Lena, Mattias Höjer, Karl-Henrik Dreborg, Tomas Ekvall, and Göran Finnveden. 2006. "Scenario types and techniques: Towards a user's guide." Futures 38 (7):723-739. doi: http://dx.doi.org/10.1016/j.futures.2005.12.002.

Carlsson-Kanyama, Annika, Karl Henrik Dreborg, HC Moll, and Dario Padovan. 2008. "Participative backcasting: a tool for involving stakeholders in local sustainability planning." Futures 40 (1):34-46.

Cork, Steven, Kate Delaney, and David Salt. 2004. Futures thinking: about landscapes, lifestyles and livelihoods in Australia. Land and Water Australia.

Costanza, Robert, Rudolf de Groot, Leon Braat, Ida Kubiszewski, Lorenzo Fioramonti, Paul Sutton, Steve Farber, and Monica Grasso. 2017. "Twenty years of ecosystem services: How far have we come and how far do we still need to go?" Ecosystem Services 28:1-16. doi: https://doi.org/10.1016/i.ecoser.2017.09.008.

de Coninck, H., A. Revi, M. Babiker, P. Bertoldi, M. Buckeridge, A. Cartwright, W. Dong, J. Ford, S. Fuss, J.-C. Hourcade, D. Ley, R. Mechler, P. Newman, A. Revokatova, S. Schultz, L. Steg, and T. Sugiyama. 2018. "Strengthening and Implementing the Global Response." In Global Warming of $1.5^{\circ} \mathrm{C}$. An IPCC Special Report on the impacts of global warming of $1.5^{\circ} \mathrm{C}$ above pre-industrial levels and related global greenhouse gas emission pathways, in the context of strengthening the global response to the threat of climate change, sustainable development, and efforts to eradicate poverty, edited by V. Masson-Delmotte, P. Zhai, H.-O. Pörtner, D. Roberts, J. Skea, P.R. Shukla, A. Pirani, W. Moufouma-Okia, C. Péan, R. Pidcock, S. Connors, J.B.R. Matthews, Y. Chen, X. Zhou, M.I. Gomis, E. Lonnoy, T. Maycock, M. Tignor and T. Waterfield. In Press.

Harmáčková, Zuzana V., and David Vačkář. 2018. "Future uncertainty in scenarios of ecosystem services provision: Linking differences among narratives and outcomes." Ecosystem Services 33:134-145. doi: https://doi.org/10.1016/j.ecoser.2018.06.005.

Hope, Pandora, Debbie Abbs, Jonas Bhend, Francis Chiew, John Church, Marie Ekström, Dewi Kirono, Andrew Lenton, Chris Lucas, Kathleen McInnes, Aurel Moise, Didier Monselesan, Freddie Mpelasoka, Leanne Webb, and Penny Whetton. 2015. "Southern and South-Western Flatlands Cluster Report, Climate Change in Australia Projections for Australia's Natural Resource Management Regions." In Cluster Reports, edited by M Ekström, Penny Whetton, Chris Gerbing, Michael Grose, Leanne Webb and James Risbey. Australia: CSIRO and Bureau of Meteorology.

Lockwood, Michael, Julie Davidson, Allan Curtis, Elaine Stratford, and Rod Griffith. 2010. "Governance Principles for Natural Resource Management." Society \& Natural Resources 23 (10):986-1001. doi: 10.1080/08941920802178214.

Malekpour, Shirin, Rebekah R Brown, Fjalar J de Haan, and Tony HF Wong. 2017. "Preparing for disruptions: A diagnostic strategic planning intervention for sustainable development." Cities 63:58-69.

McPhearson, Timon, Erik Andersson, Thomas Elmqvist, and Niki Frantzeskaki. 2015 "Resilience of and through urban ecosystem services." Ecosystem Services 12:152-156. doi: https://doi.org/10.1016/j.ecoser.2014.07.012. 
Means, Edward, Maryline Laugier, Jennifer Daw, Malcom Pirnie, Laurna Kaatz, and Marc Waage. 2010. Decision support planning methods: incorporating climate change uncertinties into water planning. Water Utility Climate Alliance.

Oteros-Rozas, Elisa, Berta Martín-López, Tim Daw, Erin L Bohensky, James Butler, Rosemary Hill, Julia Martin-Ortega, Allyson Quinlan, Federica Ravera, and Isabel Ruiz-Mallén. 2015. "Participatory scenario planning in place-based social-ecological research: insights and experiences from 23 case studies." Ecology and Society 20 (4).

Oteros-Rozas, Elisa, Berta Martìn-López, Tim M. Daw, Erin L. Bohensky, James R. A. Butler, Rosemary Hill, Julia Martin-Ortega, Allyson Quinlan, Federica Ravera, Isabel Ruiz-MallÈn, Matilda Thyresson, Jayalaxshmi Mistry, Ignacio Palomo, Garry D. Peterson, Tobias Plieninger, Kerry A. Waylen, Dylan M. Beach, Iris C. Bohnet, Maike Hamann, Jan Hanspach, Klaus Hubacek, Sandra Lavorel, and Sandra P. Vilardy. 2015. "Participatory scenario planning in place-based social-ecological research: insights and experiences from 23 case studies." Ecology and Society 20 (4). doi: 10.5751/ES-07985-200432.

Pearson, Leonie J, Sarah Park, Benjamin Harman, and Sonja Heyenga. 2010. "Sustainable land use scenario framework: Framework and outcomes from periurban South-East Queensland, Australia." Landscape and Urban Planning 96 (2):88-97.

Reason, P, and H Bradbury. 2006. Handbook of Action Research London: SAGE.

Reisinger, A., R.L. Kitching, F. Chiew, L. Hughes, P.C.D. Newton, S.S. Schuster, A. Tait, and P. Whetton. 2014. "Australasia." In Climate Change 2014: Impacts, Adaptation, and Vulnerability. Part B: Regional Aspects. Contribution of Working Group II to the Fifth Assessment Report of the Intergovernmental Panel on Climate Change, edited by V.R. Barros, C.B. Field, D.J. Dokken, M.D. Mastrandrea, K.J. Mach, T.E. Bilir, M. Chatterjee, K.L. Ebi, Y.O. Estrada, R.C. Genova, E.S. B. Girma, Kissel, A.N. Levy, S. MacCracken, P.R. Mastrandrea and L.L. White, 13711438. Cambridge, United Kingdom and New York, NY, USA: Cambridge University Press.

Sandhu, Harpinder, Beverley Clarke, Ryan Baring, Sharolyn Anderson, Claire Fisk, Sabine Dittmann, Stewart Walker, Paul Sutton, Ida Kubiszewski, and Robert Costanza. 2018. "Scenario planning including ecosystem services for a coastal region in South Australia." Ecosystem Services 31:194-207. doi: https://doi.org/10.1016/i.ecoser.2018.04.006.

Schetke, Sophie, Heera Lee, Wanda Graf, and Sven Lautenbach. 2018. "Application of the ecosystem service concept for climate protection in Germany." Ecosystem Services 29:294-305. doi: https://doi.org/10.1016/j.ecoser.2016.12.017.

Scholes, Robert J. 2016. "Climate change and ecosystem services." Wiley Interdisciplinary Reviews: Climate Change 7 (4):537-550. doi: 10.1002/wcc.404.

Serrao-Neumann, S., and D. Low Choy. 2018. "Uncertainty and future planning: the use of scenario planning for climate change adaptation planning and decision." In Developing and communicating climate change information, edited by S. Serrao Neumann, A. Coundrain and L. Coulter, 79-90. Switzerland: Springer.

Serrao-Neumann, Silvia, Melanie Cox, and Darryl Low Choy. 2019. "Bridging Adaptive Learning and Desired Natural Resource Management Outcomes: Insights from Australian Planners." Planning Practice \& Research 34 (2):149-167. doi: 10.1080/02697459.2018.1549188.

Varum, Celeste Amorim, and Carla Melo. 2010. "Directions in scenario planning literatureA review of the past decades." Futures 42 (4):355-369. 
Vella, Karen, Neil Sipe, Allan Dale, and Bruce Taylor. 2015. "Not Learning from the Past: Adaptive Governance Challenges for Australian Natural Resource Management." Geographical Research 53 (4):379-392. doi: 10.1111/1745-5871.12115.

Wood, Sylvia L. R., Sarah K. Jones, Justin A. Johnson, Kate A. Brauman, Rebecca Chaplin-Kramer, Alexander Fremier, Evan Girvetz, Line J. Gordon, Carrie V. Kappel, Lisa Mandle, Mark Mulligan, Patrick O'Farrell, William K. Smith, Louise Willemen, Wei Zhang, and Fabrice A. DeClerck. 2018. "Distilling the role of ecosystem services in the Sustainable Development Goals." Ecosystem Services 29:70-82. doi: https://doi.org/10.1016/j.ecoser.2017.10.010. 